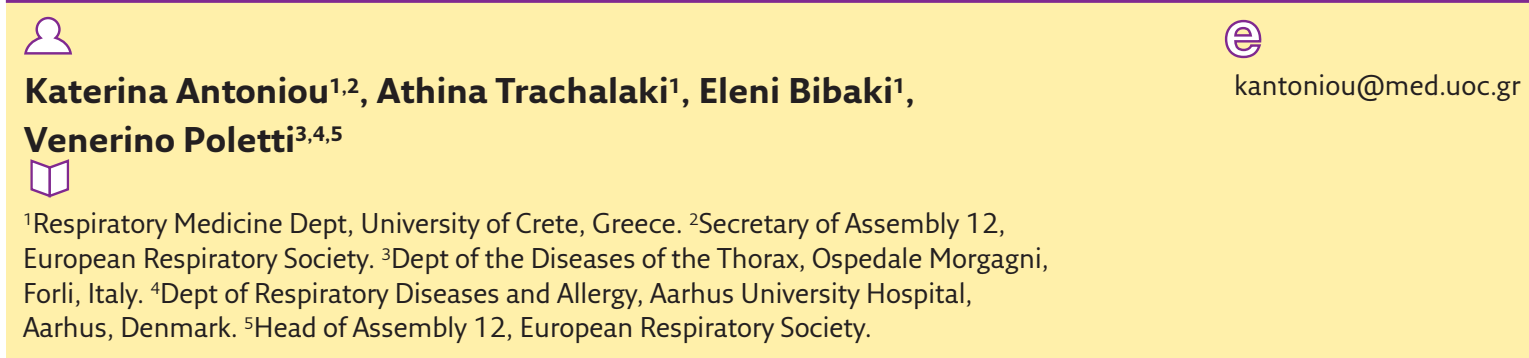

\title{
Assembly 12: interstitial lung diseases
}

\section{Meet the Assemblies}

Cite as: Antoniou K,

Trachalaki A, Bibaki E, et al. Assembly 12: interstitial lung diseases. Breathe 2018; 14 : 345-346.

Assembly 12 is a dynamic, new ERS assembly that arose following the continuous expansion of Clinical Assembly group 1.5 (diffuse parenchymal lung disease). It focuses on interstitial lung diseases (ILDs) and accommodates the following groups: 12.01) idiopathic interstitial pneumonias; 12.02) ILD/diffuse parenchymal lung diseases (DPLD) of known origin; 12.03) sarcoidosis and other granulomatous ILD/DPLD; and 12.04) rare ILD/ DPLD. Following its creation in September 2017, Assembly 12 gathered $4 \%$ of all the ERS members affiliated to an assembly. The number of members in Assembly 12 has been steadily increasing, reaching a total of 735 in August 2018. Group 12.01 (idiopathic interstitial pneumonias) is the most popular group. Young respiratory scientists have strong representation in our Assembly, up to $39 \%$ of the Assembly members are early career members.

The scientific contributions to the society from our Assembly members are growing and this year's ERS in Paris was our first promising participation as Assembly 12. The abstracts submitted by Assembly 12 members for the 2018 ERS Congress had increased by $21 \%$ compared with 2017 and the overall number of abstract sessions had also increased by $8 \%$.

The main priority of the assembly is to move forward education and research in the field of ILDs. To achieve this Assembly 12 is in constant cooperation with Assembly 3 (basic and translational sciences). To this end, several research seminars have been organised to date, the highlight being the ERS research seminar on "Integrating systems biology approach in idiopathic pulmonary fibrosis research" held in Barcelona in 2016. During this research seminar, a global initiative for fibrosis treatment was designed and supported, to serve as basis on which to build international translational research collaboration and a comprehensive, systems biology-based approach to move forward the field of research on idiopathic pulmonary fibrosis.

Since Assembly 12 originated from a group with the clinical Assembly 1, it is highly clinically oriented and maintains cooperation with other groups from Assembly 1 and the newly created Assembly 14 , especially the "interventional pulmonology" and "imaging" groups. Furthermore, due to the interplay of ILDs with lung cancer and pulmonary hypertension, our assembly cooperates with Assemblies 11 and 13.

To improve the management and standard of care of ILD patients, our members are leading several ERS task forces in collaboration with other societies, e.g. the American Thoracic Society. To date, there are three ongoing task forces: 1) thoracic complications of connective tissue diseases; 2) diagnosis and management of idiopathic 
pulmonary fibrosis: a statement; and 3) sarcoidosis treatment. The task force on Interstitial Pneumonia with Autoimmune Features published its results in 2015 [1]. Moreover, the recent WASOG (World Association of Sarcoidosis and other Granulomatous Disorders) congress, held in June 2018, Heraklion, Greece, was endorsed by ERS and our Assembly led its programme.
In summary, we are a promising, new and continually expanding Assembly, with a primary focus in the diagnosis and management of ILDs as well as basic and translational research in the field. Our aim for the future is to offer clinicians and researchers with an interest in ILDs more educational and scientific activities and to actively engage more early career members.

\section{Conflict of interest}

None declared.

\section{References}

1. Fischer A, Antoniou KM, Brown KK, et al. An official European Respiratory Society/American Thoracic Society research

statement: interstitial pneumonia with autoimmune features. Eur RespirJ 2015; 46: 976-987 